\title{
40. An Analysis of Urbanization and its Influence on Domestic Water Use in China 中国の都市化に伴う生活用水量の影響に関する研究
}

\author{
Ji HAN*, AKIO Onishi**, Hidefumi IMURA*** \\ 韓龮*, 大西暁生**, 井村秀文***
}

\begin{abstract}
In the last decades, China has experienced a rapid process of urbanization, accompanied by a large flow of population migration. It is recognized that large amount of population migration and urbanization would bring impacts on regional environment. These impacts may cover many aspects, such as water use, energy consumption, land use change and pollution, etc. This paper focuses on domestic water use issue as an example.

Firstly, the mechanism of population migration is examined by using both nationwide time-series data and 2000 Census data. Secondly, alternative scenarios of economic development, population migration and urbanization in China until year 2020 are formulated, assuming socio-economic and policy scenarios in the future. Finally, impact of population migration on domestic water use is evaluated.
\end{abstract}

KEYWORDS: Population migration, Urbanization, Domestic water use

\section{Introduction}

Since the start of economic reform in 1978, China has been experiencing a rapid urbanization accompanied by a large flow of rural to urban migration. From 1978 to 2000, China's urbanization level grew from $18 \%$ to $36 \%$. The total migration from 1995 to 2000 amounted to 128 million. What do this timing and extent of urbanization imply? What is the dynamics of population migration? And more importantly, what will the regional environment change take place due to the population migration and urbanization in China? Although the environmental impacts cover many aspects, such as water use, energy consumption, land use change, etc., this paper just emphasizes on domestic water use issue as an example.

Regarding China's population migration issues, many studies have been conducted in the last decades. Wu (1996) surveyed the literature on China's rural-to-urban labor migration ${ }^{1)}$. Wang (1999) pointed out that huge urhan-rural income gap and massive rural surplus labor were the main drivers of the rapid increase of rural migrants in cities ${ }^{2}$. Yan (2004) examined the determinants of inter-provincial migration based on the national census data ${ }^{3}$. These studies provide an important insight into the actual situation. However, most of them focused on whole China. Thus the regional disparities of population migration and its influence on domestic water use have not yet been analyzed. Besides, water resource issue in China also has been paid much attention nationally and internationally. Chinese Academy of Engineering (2001) evaluated the current water resource issues and analyzed the future trend of water supply and demand ${ }^{4}$. Japan Bank for International Cooperation (2004) studied the water balance between supply and demand in China's Yellow River Basin ${ }^{5}$. All of these studies analyzed water resource in China comprehensively. However, while considering the socio-economic development, especially the

*名古屋大学大学院 工学研究科 社会基盤専攻 Graduate School and School of Engineering, Nagoya University, Furo-cho, Chikusa-ku, Nagoya City, Japan 464-8601.

**総合地球環境学研究所 Research Institute for Humanity and Nature, 457-4 Motoyama, Kamigamo, Kita-ku, Kyoto City, Japan 603-8047.

***名古屋大学大学院 環境学研究科 都市環境学専攻 Graduate School of Environmental Studies, Nagoya University, Furo-cho, Chikusa-ku, Nagoya City, Japan 464-8601. 
population growth, most of the studies take it as an exogenous variable or just extrapolate the historical trend. Those studies, starting from the understanding of China's population migration, analyzing its future trend by considering socio-economic changes, and finally examining its impact on domestic water use, are limited.

In order to bridge the data gaps and to provide bases for policy deliberations in China regarding sustainable development, this paper attempts to a) analyze the mechanism of population migration by using both nationwide time-series data and 2000 Census data; b)formulate scenarios of economic development, population migration and urbanization in China toward the year 2020 by considering possible socio-economic development in the future; c) evaluate the impact of population migration on domestic water use.

\section{Characteristics of Population Migration and Urbanization in China}

\subsection{Scales and contribution of rural-to-urban migration to urbanization 1983-2003}

In order to see the contribution of migration to urbanization from 1983 to 2003, the urban population growth was decomposed into two parts: natural growth and net migration. As showed in table 1, the contribution of rural-to-urban migration to urban growth was $77 \%$ in $1983-1989,67 \%$ in $1990-1995$ and $86 \%$ in 1996-2003. Rural-to-urban migration has become the dominant source of Chinese urban growth.

Table 1 Contribution of rural-to-urban migration to urban population growth

\begin{tabular}{cccccc}
\hline \multirow{2}{*}{ Period } & \multirow{2}{*}{$\begin{array}{c}\text { Annual growth of total } \\
\text { urban pop. (million) }\end{array}$} & \multicolumn{2}{c}{ Annual natural growth of pop. } & \multicolumn{2}{c}{ Annual net migration } \\
\cline { 3 - 6 } & Number (million) & Share (\%) & Number (million) & Share (\%) \\
\hline $1983-1989$ & 11.52 & 2.69 & 23.3 & 8.83 & 76.7 \\
$1990-1995$ & 9.39 & 3.08 & 32.8 & 6.31 & 67.2 \\
$1996-2003$ & 21.50 & 2.96 & 13.8 & 18.54 & 86.2 \\
\hline $1983-2003$ & 14.71 & 2.90 & 19.7 & 11.81 & 80.3 \\
\hline
\end{tabular}

Source: calculated from China Statistical Yearbook (NBS, 2000, 2004) and China Population Statistics Yearbook (NBS, 2004)

\subsection{Spatial patterns of population migration}

\section{(A) Intra-provincial migration}

According to the $5^{\text {th }}$ National Census in 2000, within the total 128 million migrants, $73 \%$ were identified as the intra-provincial migrants, while $27 \%$ belonged to inter-provincial migration.

\section{(B) Inter-provincial migration}

For inter-provincial migration, as showed in figure 1 and 2, the migration was primarily from the middle and western regions toward the eastern region. Guangdong, Shanghai, Zhejiang and Beijing became the concentrated centers. While Sichuan, Hunan, Anhui, Jiangxi were the largest senders of emigrants.

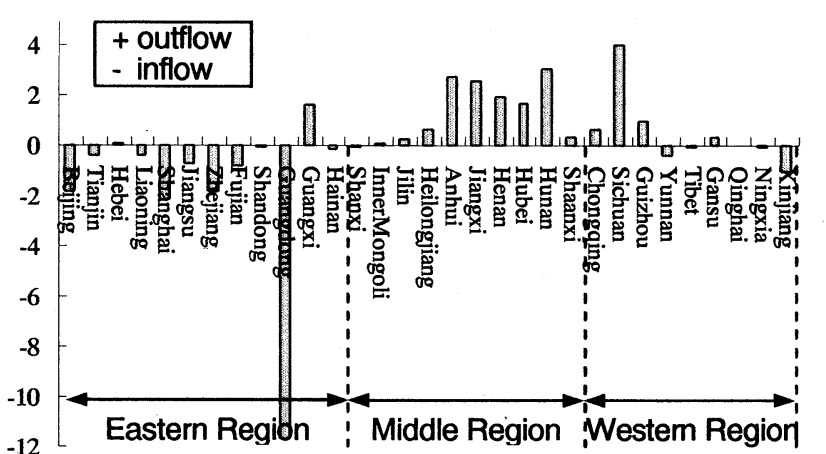

Notes: Eastern Region includes: Beijing, Tianjing, Hebei, Liaoning, Shanghai, Jiangsu, Zhejiang, Fujian, Shandong, Guangdong, Guangxi, Hainan. Middle Region includes: Shanxi, Inner Mongolia, Jilin, Heilongiiang, Anhui, Jiangxi, Henan, Hubei, Hunan, Shannxi. The rest belong to Western Region.

Figure 1 Provincial-level net in and out population migration (Unit: million)

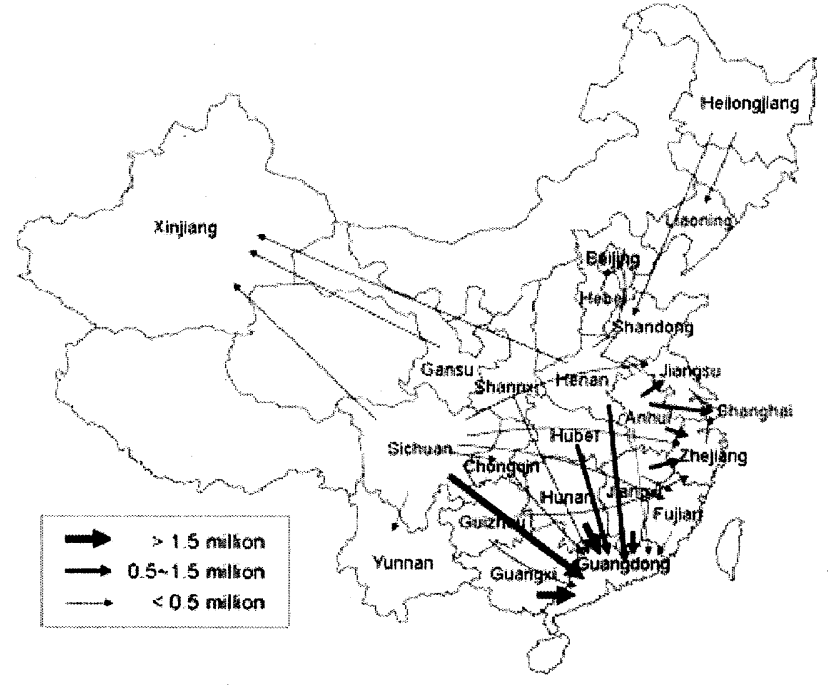

Figure 2 The 31 largest inter-provincial migration flow in 1995-2000 in China 


\section{(C) Migration between rural and urban areas}

The total population migration can be divided into 4 categories in terms of the type of origin and destination. They are "rural-to-urban", "rural-to -rural", "urban-to-rural" and "urban-to-urban". Among them, "rural-to-urban" was the largest one which shared $40.7 \%$ of the total migration. The second was "urban-to-urban" migration, which shared $37.2 \%$ of the total. The third was "rural-to-rural" migration, which shared $18.2 \%$ of the total. And "urban-to-rural" was the smallest, which only accounted for $3.9 \%$ of the total migration". In short, the primary population migration in China was the flow from rural areas to cities.

\section{Empirical Analyses of the Mechanism of Population Migration}

\subsection{Analysis of time-series data}

As discussed in the theories of development economy (Harris-Todaro, 1970), rural-to-urban migration should be a consequence of economic development ${ }^{7}$. The following model of national migration with time-series data in 1983-2003 was used to validate the theoretical assumption in China.

$$
\ln M_{t}=C+a_{1} \ln Y_{t}+a_{2} \ln G_{t}+a_{3} \ln U_{t}+a_{4} \ln R_{t}+a_{5} \ln T
$$

where, $M$ is net rural-to-urban migration; $Y$ is urban/rural per capita income ratio; $G$ is per capita GDP; $U$ is unemployment rate in cities; $R$ is rural population per arable land; $T$ is time dummy; $C$ is constant.

In order to eliminate the effect of multicollinearity among variables, stepwise estimation method was adopted. Table 2 shows the results with and without stepwise estimation.

Table 2 Determinants of rural-to-urban migration in China 1983-2003

\begin{tabular}{ccccc}
\hline \multirow{2}{*}{ Variables } & \multicolumn{2}{c}{ Full model } & \multicolumn{2}{c}{$\begin{array}{c}\text { Model with stepwise } \\
\text { estimation }\end{array}$} \\
\cline { 2 - 5 } & coefficients & $t$ statistic & coefficients & $t$ statistic \\
\hline Constant & -16.44 & -1.43 & $-21.74^{* * *}$ & -4.87 \\
$Y$ & -1.63 & -1.59 & & \\
$G$ & $4.32^{* * *}$ & 4.39 & $4.72^{* * *}$ & 6.12 \\
$U$ & $-1.42^{*}$ & -1.93 & $-1.82^{* *}$ & -2.66 \\
$R$ & -1.32 & -0.38 & & \\
$T$ & $-2.61^{* *}$ & -2.41 & $-3.38^{* * *}$ & -5.24 \\
\hline Adjusted $R^{2}$ & \multicolumn{3}{c}{0.76} & 0.75 \\
$F$ statistic & \multicolumn{2}{c}{$13.64^{* * *}$} & $21.18^{* * *}$ \\
\hline *Level of significance: $10 \% ;$ & **Level of significance: $5 \% ;$ \\
*** Level of significance: $1 \%$. &
\end{tabular}

- Economic level (measured by $G$ ) has a significant and positive effect on rural-to-urban migration.
- Urban unemployment has a significant and negative effect on rural-to-urban migration.

- The variables of urban/rural income ratio and rural population per arable land were supposed to have positive effect on rural-to-urban migration. But during the period 1983-2003 in China, the ranges of urban/rural income ratio (1.9-3.2) and rural population per arable land (8.0-9.1) changed little, causing a migration that did not respond significantly to these two variables.

- The significant and negative coefficient of $T$ indicates a downward time trend in the level of migration. This may result from the administrative controls on the rural-to-urban migration.

\subsection{Analysis of cross-section data}

In order to further describe the patterns and mechanisms of population migration, an analytical model is established based on the cross-section data of 2000 Census.

$$
\begin{aligned}
\ln M_{i j}= & C+\alpha_{1} \ln \left(Y_{j} / Y_{i}\right)+\alpha_{2} \ln \left(G D P R_{j} / G D P R_{i}\right)+\alpha_{3} \ln \left(M_{i j} / \sum M_{i j}\right) \\
& +\alpha_{4} \ln \left(D I S_{i j}\right)+\alpha_{5} \ln \left(U_{j} / U_{i}\right)+\alpha_{6} \ln \left(S_{j} / S_{i}\right)
\end{aligned}
$$

where, $M_{i j}$ is migration from province $\mathrm{i}$ to $\mathrm{j} ; Y$ is provincial per capita income; GDPR is annual growth rate of provincial GDP; $M_{i j} / \sum M_{i j}$ is migration stock (measured by the proportion of emigrants from province $i$ to each immigration province $j$. It implies the influence of old migrants on new migrants who plan to move); $D I S_{i j}$ is distance between province $i$ and $j$ (measured by the shortest railway length between capital cities of two provinces); $U$ is urban unemployment rate; $S$ is share of the 2 nd and 3rd industrial employment.

Table 3 shows the results. And the major findings are as follows. 
- In the eastern region, income gap is the most important determinant affecting migration.

- In the middle region, the share of second and third industrial employment is the most important determinant affecting migration.

- In the western region, GDP growth rate is the most important determinant affecting migration.

- In whole China, income gap and migration stock have significant and positive effects on migration, while distance has a significant and negative effect on migration.

In sum, the most important determinants of inter-provincial migration are income gap, migration stock and distance. Income gap and migration stock encourage migration while the distance discourages migration.

Table 3 Determinants of inter-provincial migration in China (with stepwise estimation)

\begin{tabular}{|c|c|c|c|c|c|c|c|c|}
\hline \multirow[t]{2}{*}{ Independent variables } & \multicolumn{2}{|c|}{ Eastern Region } & \multicolumn{2}{|c|}{ Middle Region } & \multicolumn{2}{|c|}{ Western Region } & \multicolumn{2}{|c|}{ Whole China } \\
\hline & Coefficients & $t$ statistic & Coefficients & $t$ statistic & Coefficients & $t$ statistic & Coefficients & $t$ statistic \\
\hline$Y$ & $0.84^{* * *}$ & 10.58 & & & $0.43^{* *}$ & 2.39 & $0.62^{* * *}$ & 9.53 \\
\hline GDPR & & & & & $2.90^{* * *}$ & 7.17 & & \\
\hline Mstock & $0.77^{* * *}$ & 20.84 & $0.72 * * *$ & 21.52 & $0.66^{* * *}$ & 12.55 & $0.64 * * *$ & 23.89 \\
\hline DIS & $-0.28 * * *$ & -3.42 & $-0.42 * * *$ & -5.00 & $-1.13 * * *$ & -7.96 & $-0.83 * * *$ & -13.17 \\
\hline \multicolumn{9}{|l|}{ Unemploy } \\
\hline$S$ & & & $0.92 * * *$ & 6.59 & & & & \\
\hline Constant & $5.25^{* * *}$ & 9.98 & $6.69^{* * *}$ & 11.81 & $10.50 * * *$ & 11.63 & $8.74^{* * *}$ & 20.56 \\
\hline Adjusted $R^{2}$ & \multirow{2}{*}{\multicolumn{2}{|c|}{$\begin{array}{c}0.77 \\
\end{array}$}} & \multirow{2}{*}{\multicolumn{2}{|c|}{$\begin{array}{c}0.82 \\
02 * * *\end{array}$}} & \multirow{2}{*}{\multicolumn{2}{|c|}{$\begin{array}{c}0.61 \\
107.40^{* * *}\end{array}$}} & \multirow{2}{*}{\multicolumn{2}{|c|}{$\begin{array}{c}0.65 \\
567.27 * * *\end{array}$}} \\
\hline$F$ statistic & & & & & & & & \\
\hline
\end{tabular}

${ }^{*}$ Level of significance: $10 \%$; ${ }^{* *}$ Level of significance: $5 \%$; ${ }^{* *}$ Level of significance: $1 \%$.

\section{Scenarios of Population Migration and its Impact on Domestic Water Use}

\subsection{Projection of population migration}

This projection starts from Lowry's migration model (Eq. 3).

$$
M_{i j}=k \frac{U_{i}}{U_{j}} \times \frac{W_{j}}{W_{i}} \times \frac{L_{i} L_{j}}{D_{i j}}
$$

In which, $M_{i j}$ is migration from province $i$ to $j ; U$ is the unemployment rate; $W$ is the manufacturing wage; $L$ is the labor force; $D_{i j}$ is the distance between province $i$ and $j ; k$ is a constant. By substituting some variables for more readily available data, Lowry model is modified as

$$
M_{i j}=k \frac{U_{i}}{U_{j}} \times \frac{y_{j}}{y_{i}} \times \frac{P_{i} P_{j}}{D_{i j}}
$$

where, $y$ is average provincial per capita income; $P$ is provincial population. Suppose the new income in province $i$ after the migration can be expressed like $y_{i}^{\prime}=y_{i}+\Delta y_{i}$

Then, to first order,

$$
\Delta\left(\frac{y_{j}}{y_{i}}\right) \approx\left(\frac{y_{j}}{y_{i}}\right) \cdot\left(\frac{\Delta y_{j}}{y_{j}}-\frac{\Delta y_{i}}{y_{i}}\right)
$$

Ignoring the second-order effect of a change in population due to migration and changes in unemployment associated with income change. Using (4) and (5), the population change is

$$
\Delta P_{i}=-\sum_{j \neq i}\left(M_{i j}-M_{j i}\right)=-\sum_{j \neq i} \Delta M_{i j}=-k \sum_{j \neq i} \frac{P_{i} P_{j}}{D_{i j}}\left(\frac{\Delta y_{j}}{y_{j}}-\frac{\Delta y_{i}}{y_{i}}\right)
$$

Eq. (6) is used for the projection of inter-provincial migration. In the implementation of model, $\mathrm{k}$ is set as 1000 $\mathrm{m} /$ person $^{8)} . D_{i j}$ is the shortest railway length between provincial capitals. The overall negative sign means that the change of provincial population is the negative of net migration flow out of province. $P$ is calculated as a result of natural growth and population migration. In each year, it is assumed that $10 \%$ of inter-provincial immigrants will be counted as the registered residents to local population.

Similarly, the adjustment of urban and rural population within one province can be expressed as 


$$
\Delta P_{u}=-\Delta P_{r}=-k \frac{P_{r} P_{u}}{D_{r u}}\left(\frac{\Delta y_{r}}{y_{r}}-\frac{\Delta y_{u}}{y_{u}}\right)
$$

\subsection{Projection of economic development}

In order to achieve the target of sustainable development of whole nation, regional convergence must be considered as an important policy focus in the model. The model is based on the following hypotheses: Firstly, if other things being equal, per capita GDP growth rate is higher for regions with lower per capita GDP. Secondly, per capita income is a constant proportion of per capita GDP. Over the whole scenario, they share the same growth rate. The national GDP growth rate is specified as an exogenous variable, which is set as 7\% in 2001-2010, and $6.5 \%$ in 2011-2020. Each province converges in the following way.

$$
r=r_{0}-\chi \lambda \ln \left(y / y_{0}\right)
$$

where, $r$ is the growth rate of the provincial per capita income $y$; $r_{0}$ is the growth rate of per capita income $y_{0}$ in the reference region; $\lambda$ is the coefficient, set as $2.5 \%$ (from Barro and Martin, 2003) ${ }^{9}$; $X$ is the economic convergence parameter of each province.

As for the urban/rural income ratio, provinces within the region converge toward the target over scenario at a convergence rate. Since there are no data that directly give an estimate for this rate. There are only data for the change of urban/rural income ratio. Between 1978 and 2003, the national ratio varied between $-5 \%$ and 5\% annually. Based on the historical performance, a convergence rate of $5 \%$ per year is assumed. And we set the national target that urban/rural income ratio will decrease at the rate of $0.4 \%$ per year ${ }^{8)}$.

\subsection{Projection of domestic water use}

In this model, provincial domestic water use (PW) can be calculated as:

PW $=$ urban pop.$\times$ urban domestic water use unit + rural pop.$\times$ rural domestic water use unit

where, domestic water use unit in rural and urban areas are estimated according to the research result of Chinese Academy of Engineering ${ }^{4)}$. In scenario analyses, urban domestic water use unit will increase to $209 \mathrm{~L} /$ (person $\cdot d$ ) in 2020. And the rural unit will increase to $105 \mathrm{~L} /$ (person·d) in 2020.

\subsection{Model results}

Table 4 shows some major results of socio-economic development. And in order to evaluate the impact of population migration on domestic water use, domestic water uses calculated by two methods are compared at regional level (figure 3). Method A considers the effect of population migration and urbanization on domestic water use by using the projection models stated above. Method B just bases on the observation of historical patterns, and then extrapolates the domestic water use.

Table 4 Selected outputs from projection models

\begin{tabular}{ccccccc}
\hline & Regions & 2000 & 2005 & 2010 & 2015 & 2020 \\
\hline \multirow{4}{*}{ GDP } & China & 9.72 & 13.74 & 19.27 & 26.52 & 36.32 \\
(trillion yuan) & Eastern & 5.77 & 8.14 & 11.38 & 15.63 & 21.38 \\
& Middle & 2.79 & 3.94 & 5.52 & 7.57 & 10.33 \\
& Western & 1.15 & 1.66 & 2.37 & 3.31 & 4.61 \\
\hline \multirow{4}{*}{ Population } & China & 1,242 & 1,282 & 1,321 & 1,359 & 1,398 \\
(million) & Eastern & 528 & 553 & 579 & 607 & 636 \\
& Middle & 468 & 476 & 484 & 490 & 496 \\
& Western & 247 & 253 & 258 & 262 & 267 \\
\hline \multirow{4}{*}{ Urbanization } & China & 35.96 & 39.30 & 44.44 & 49.64 & 54.74 \\
(\%) & Eastern & 44.96 & 48.06 & 54.55 & 60.85 & 66.72 \\
& Middle & 31.38 & 35.34 & 39.54 & 43.90 & 48.36 \\
& Western & 24.50 & 27.60 & 30.92 & 34.42 & 38.07 \\
\hline
\end{tabular}

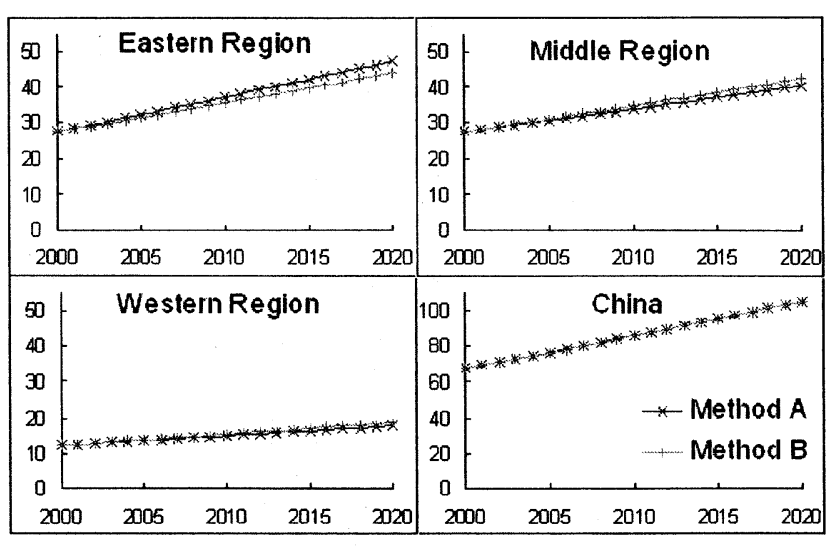

Figure 3 Regional domestic water use (unit: billion $\mathbf{~ m}^{\mathbf{3}}$ ) 
In whole China, the domestic water use estimated by method A and B are nearly the same. But the regional domestic water uses calculated by method A and B are different. In the eastern region, domestic water use affected by population migration is larger than the value just extrapolated by historical trend. While the situations in the middle and western regions are opposite. Apparently, because of population migration, large amount of people will move to eastern provinces and urban areas, which will definitely cause the disparity of domestic water use increasing among regions. If just estimating the domestic water demand without tying to specific socio-economic and policy influences, the result of projected future domestic water use will deviate largely from the possible amount.

\subsection{Model accuracy test}

For model accuracy, actual population and GDP in each province of 2004 is compared with model projection value. Figure 4 shows the results. $R^{2}$ in each case is close to 1.0 .

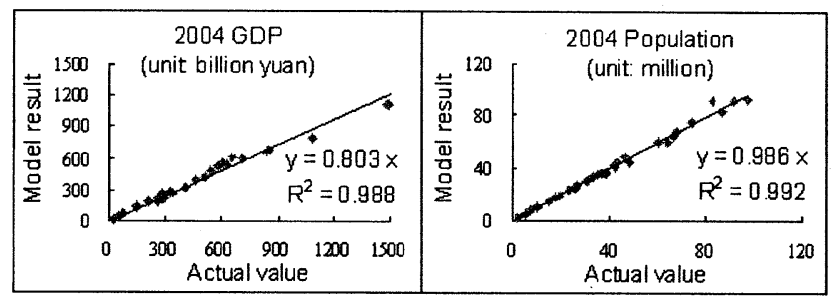

\section{Conclusion and Discussion}

Figure 4 Model accuracy tests

- The main source of China's urbanization in the past two decades was the rural-to-urban migration, which resulted from the rapid economic growth.

- The most important determinants of inter-provincial migration in China are income gap, migration stock and distance. Income gap and migration stock encourage migration while distance discourages migration.

- Due to the uneven regional economic development, large amount of people move from middle and western regions to eastern region, rural to urban areas. This also results in the disparity of domestic water use among regions. In eastern region, population migration would make the future domestic water use become larger than that amount just extrapolated by historical trend, while without considering specific socio-economic development. In middle and western regions, situations are opposite.

- Comparing to the projection method without considering specific socio-economic and policy influences, the projection models developed in this paper are more reasonable and precise in evaluating environmental impacts caused by population migration in the future.

Based on the models established in this study, many potential uses and further studies can be derived. For example, by adding some reasonable assumptions to the projection models, the authors plan to study environmental impacts of population migration and urbanization with respect to urban housing issues, energy consumption issues, land use changing issues and environmental pollution issues, etc. in the future.

\section{REFERENCES}

1) Wu H.X., Li Z., Rural-to-urban migration in China. Asian-Pacific Economic Literature, 11, 54-67, 1996.

2) Wang F., Zuo X., Inside China's cities: Institutional barriers and opportunities for urban migrants. American Economic Review, 89(2), 276-280, 1999.

3) Yan S.P., Inter-provincial migration and its determinants in China. Asian Economy, 45(4), 2-20, 2004. (in Japanese)

4) Liu C.M, Chen Z. K., Evaluation of current water resources and analyses of the water supply and demand trends in China. Beijing, CWHR Press. 2001. (in Chinese)

5) JBICI research paper No.28, Water resources in North China, analyses of water supply and demand balance in Yellow River Basin. 2004. (in Japanese)

6) Cai F., Wang D.W., Population migration as marketization: analysis of 5th census data. Population Science of China, 5, 11-19, 2003. (in Chinese)

7) Harris J.R, Todaro M.P, Migration, unemployment and development: A two-sector analysis. American Economic Review, 60, 126-142, 1970.

8) Eric Kemp-Benedict, Background report on quantitative scenarios: For the CCICED SUS Task Force, 2005.

9) Barro R.J, Xavier Sala-i-Martin, Economic Growth, $2^{\text {nd }}$ Edition, Cambridge, MIT Press, 2003. 